\title{
Optimised fertilisation with zeolitites containing Plant Growth Promoting Rhizobacteria (PGPR) in Ranunculus asiaticus
}

\author{
Prisa Domenico* \\ CREA Research Centre for Vegetable and Ornamental Crops, Council for Agricultural Research and Economics, Via dei \\ Fiori 8, 51012 Pescia, PT, Italy.
}

Publication history: Received on 14 January 2020; revised on 20 January 2020; accepted on 22 January 2020

Article DOI: https://doi.org/10.30574/gscbps.2020.10.1.0011

\begin{abstract}
In this study, the possibility of optimizing the use of fertilizers on Ranunculus asiaticus by adding chabazite with Plant Growth Promoting Rhizobacteria (PGPR) to the substrate was evaluated. The five experimental groups in cultivation were: i) group without zeolites (CTRL), irrigated with water and substrate previously fertilized; ii) group with natural chabazite (CN) and 100\% fertilised substrate; iii) group with chabazite enriched with PGPR (CM) and 100\% fertilised substrate; iv) group with natural chabazite (CN2) and 50\% fertilised substrate; v) group with chabazite enriched with PGPR (CM2) and 50\% fertilised substrate. All plants treated with chabazite (CN and CN2) and chabazite enriched with PGPR (CM and CM2) showed a significant increase in the agronomic characteristics analysed compared to the untreated control (CTRL). The results show that the microorganisms are able to improve the performance of zeolitite, probably increasing the efficiency of nutrient and water absorption by the roots. This is also evident when evaluating physiological parameters where the photosynthesis rate and chlorophyll content are significantly better in (CM) and (CM2) than in (CN) and (CN2). Zeolites can act as a "home" for microorganisms, as is normally the case in nature with clays. In fact, under conditions of water stress, microorganisms take refuge inside the clay particles until the environmental conditions are suitable again to colonize the soil. Zeolites are able to actively interact with the organic components present in the soil or brought with fertilization, and have the ability to make more available the mineral and nutritional components present within their crystalline lattice, according to the needs of the plant.
\end{abstract}

Keywords: Ornamentals; Sustainable applications; Stimulation; Rhizosphere; PGPR

\section{Introduction}

The buttercup, or Ranunculus asiaticus, belongs to the family of the Ranunculaceae and is utilized in gardens and terraces, as it can be cultivated also in pots. The buttercup bulb is no larger than $10 \mathrm{~cm}$ and produces delicious, unscented flowers with a diameter of $5 \mathrm{~cm}$, which can be yellow, orange, red, pink or white. The plant reaches a maximum height of $40 \mathrm{~cm}$ and its leaves are rather light green [1]. The buttercup particularly likes the sun and must be exposed in a suitable position. The best place of exposure for a buttercup is sunny in some hours of the day, the perfection is reached if the plant is exposed to direct sunlight in the less hot hours and is more protected in the warmer ones. Remember that during the growing phase (the plant has an extremely premature flowering compared to others) the buttercup does not like temperatures above $15^{\circ} \mathrm{C}$, paradoxically the buttercup fears more the cold than the heat. The species of this genus have a worldwide distribution and in any case temperate climate zones; therefore, besides the Mediterranean and Europe, central Asia north of the great mountain ranges, in the region of Cape South Africa, California, Florida and central Chile. The habitat is the most varied: meadows, marshy areas, rocky environments, uncultivated areas and more. The Ranunculus asiaticus L. (Asian buttercup) perennial, native to Greece, Turkey and Iran, $30-45 \mathrm{~cm}$ tall, has given origin to several hybrids and varieties.[2].

\footnotetext{
${ }^{*}$ Corresponding author

E-mail address: domenico.prisa@crea.gov.it
} 
Zeolites are particular diagenized pyroclastic rocks with peculiar properties (high and selective cation exchange capacity, high water retention, micro and macro textile porosity) that justify their advantageous applications in the agronomic and ornamental field [3]; in particular, chabazitic- zeolites (a type of which the Italian soils very rich) can be used in substrates to replace inert matrices (vermiculite, perlite, pumice) with significant effects on plant development and resistance to stress, reducing the use of water and fertilizers $[4,5,6,7]$. Whether due to the presence of zeolites or the consistency of the rocks, zeolites have a high (130-200 meq/100g) and selective (mainly for $\mathrm{NH}_{4}$ and $\mathrm{K}^{+}$) cation exchange capacity, reversible dehydration, permeability and high water retention, all useful in agricultural, horticultural and floricultural applications [5,6]. Zeolites were used in this experiment because they have several interesting characteristics for use in agriculture, horticulture and in particular in tomato [4], celery [5], zucchini and melon [8], and vegetables and fruit $[9,10]$ and ornamental plants $[11,12,13]$. In particular the binomial zeolites and microorganisms seems very interesting as found in other experiments to improve the qualitative characteristics of plants, nutrient uptake and resistance to biotic and abiotic stress $[14,15]$.

In this study, the possibility of optimizing the use of fertilizers on Ranunculus asiaticus (Figure 1) by adding zeolites with Plant Growth Promoting Rhizobacteria to the substrate was evaluated.

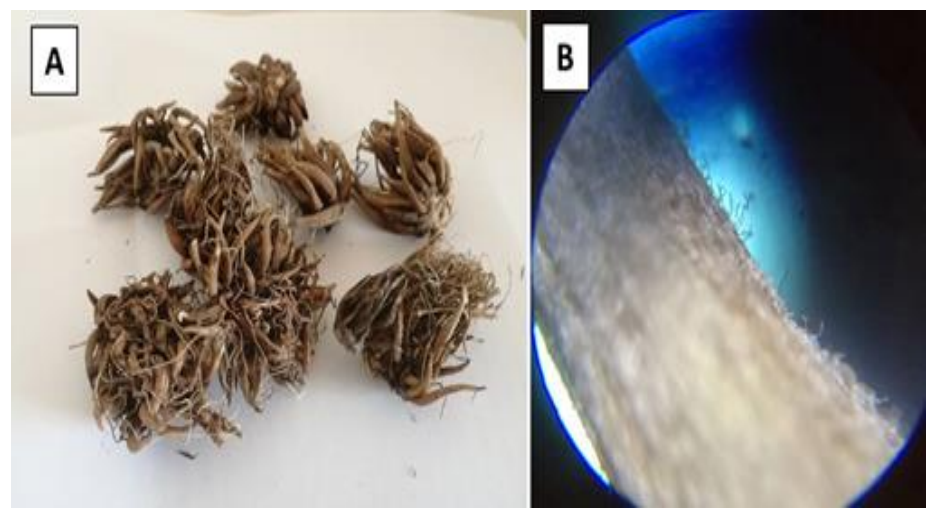

Figure 1 Detail of rhizomes (A) and root hairs (B) in Ranunculus asiaticus

\section{Material and methods}

\subsection{Greenhouse experiment and growing conditions}

The experiments, started in March 2019, were conducted in the greenhouses of CREA-OF in Pescia (Pt), Tuscany, Italy $\left(43^{\circ} 54^{\prime} \mathrm{N} 10^{\circ} 41^{\prime} \mathrm{E}\right)$ on Ranunculus asiaticus plants. The plants were placed in $\emptyset 14 \mathrm{~cm}$ pots; 30 plants per thesis, divided into 3 replicas of 10 plants each. All plants were fertilized with a controlled release fertilizer $(4 \mathrm{~kg} \mathrm{~m}-3$ Osmocote Proß, 6 months with $190 \mathrm{~g} / \mathrm{kg} \mathrm{N}, 39 \mathrm{~g} / \mathrm{kg} \mathrm{P}, 83 \mathrm{~g} / \mathrm{kg} \mathrm{K}$ ) mixed with the growing medium before transplanting. The five experimental groups in cultivation were:

- $\quad$ Group without zeolites (CTRL) (peat 100\%), irrigated with water and substrate previously fertilized;

- Group with natural chabazite (CN) (peat 80\% + chabazite 20\%) and 100\% fertilised substrate;

- Group with chabazite enriched with PGPR (CM) (peat 80\% + chabazite 20\%) and 100\% fertilised substrate. (Patented formula rif.28106IT/MB/BF)

- $\quad$ Group with natural chabazite (CN2) (peat 80\% + chabazite 20\%) and 50\% fertilised substrate;

- Group with chabazite enriched with PGPR (CM2) (peat 80\% + chabazite 20\%) and 50\% fertilised substrate.

All chabazite products were supplied by Balco Greenline of Sassuolo (M0). The chabazitic- zeolites had the following characteristics: 1) qualitative-quantitative mineralogical analysis (\% by weight with standard deviations in brackets) carried out by X-ray powder diffractogram according to the RIETVELD-RIR methodology [16]: chabazite 66.2 (1.0); phillipsite 2.4 (0.5); mica 5.6 (0.6); K-feldspar 10.3 (0.8); pyroxen 2.2 (0.5); volcanic glass 13.3 (1.5); 2) Total zeolithic content (\%): 68.6 (1.3), of which 66.2 due to chabazite and 2.4 from phillipsite. Cation exchange capacity (in meq/g with standard deviation in brackets) determined using the methodology described in Gualtieri et al. (1999) [17]: 2.15 (0.15) of which 1.42 due to $\mathrm{Ca}, 0.04$ to $\mathrm{Mg}, 0.05$ to $\mathrm{Na}$ and 0.64 to K. The chabazite with added PGPR had a microbial count of $4.2 \times 10^{6} \mathrm{ufc} / \mathrm{g}$ of zeolites. The $\mathrm{pH}$ of the zeolite was 6.9. For the experimentation of plant growth was used $\varnothing 3-6 \mathrm{~mm}$. 
The plants were watered 3 times a week and grown for 8 months. The plants were irrigated with drip irrigation. The irrigation was activated by a timer whose program was adjusted weekly according to climatic conditions and the fraction of leaching. On September 3, 2019, the plant height, leaves number, the vegetative and root weight, and flowers number and diameter were recorded. Ten days before the destructive analysis, the chlorophyll content was evaluated (FieldScout CM 1000 Chlorophyll Meter); SPAD index was measured on three leaves of each plant (30 measurements per treatment), net photosynthesis (Pn) (LI-6400XT Portable Photosynthesis System).

\subsection{Statistics}

The experiment was carried out in a randomized complete block design. Collected data were analysed by one-way ANOVA, using GLM univariate procedure, to assess significant $(P \leq 0.05,0.01$ and 0.001$)$ differences among treatments. Mean values were then separated by LSD multiple-range test $(P=0.05)$. Statistics and graphics were supported by the programs Costat (version 6.451) and Excel (Office 2010).

\section{Results}

\subsection{Plant growth}

All plants treated with chabazite (CN and CN2)) and chabazite enriched with PGPR (CM and CM2) showed a significant increase in the agronomic characteristics analysed compared to the untreated control (CTRL). Treatment with chabazite enriched with PGPR (CM) was significantly better than with natural chabazite (CN). The thesis with chabazite and $50 \%$ fertilization (CN2) were also significantly better than the $100 \%$ fertilized control (CTRL) and chabazite enriched with PGPR and $50 \%$ fertilization (CM2) was significantly better than treatment with natural chabazite and $50 \%$ fertilization (CN2).

The results show that the microorganisms are able to improve the performance of zeolites, probably increasing the efficiency of nutrient and water absorption by the roots. This is also evident when evaluating physiological parameters where the photosynthesis rate and chlorophyll content are significantly better in (CM) and (CM2) than in (CN) and (CN2).In Ranunculus, (Table 1) the plant height was $30.36 \mathrm{~cm}$ in (CM), $27.17 \mathrm{~cm}$ (CM2) and $25.66 \mathrm{~cm}(\mathrm{CN})$ which behaved in the same way, $23.01 \mathrm{~cm}$ (CN2) which was significantly better than $17.52 \mathrm{~cm}$ of the untreated control (CTRL) (Figure 2). For the number of leaves, 42.80 (CM) was the most efficient treatment, then 38.40 (CN), 37.60 (CM2) and 35.40 (CN2) which behaved in the same mode. Finally the worst treatment was the control (CTRL) with 30.20 leaves. There was a significant increase in vegetative biomass $48.26 \mathrm{~g}(\mathrm{CM})$, which was significantly better than $45.66 \mathrm{~g}(\mathrm{CN})$, $45.54 \mathrm{~g}$ (CM2), $43.41 \mathrm{~g}$ (CN2) and untreated control $42.58 \mathrm{~g}$ (CTRL). The treatment (CM) for radical biomass was also significantly better than the others with $42.90 \mathrm{~g}(\mathrm{CM})$, compared to $39.50 \mathrm{~g}$ (CM2) and 38.64 (CN) which behaved in the same way. Finally, the treatment (CN2) with $35.76 \mathrm{~g}$ was significantly better than the control (CTRL) with $32.24 \mathrm{~g}$ (Figure 3).For the number of flowers the treatments (CM) with 31.40, (CM2) with 30.40 and (CN) with 30.20 were significantly better, compared to 21.80 (CN2) and 16.20 (CTRL).

For the flower diameter, the treatment (CM) was also the best with $4.08 \mathrm{~cm}$, compared to (CM2) with $3.42 \mathrm{~cm}$, (CN) 3.40 $\mathrm{cm}$ and CN2 with $3.02 \mathrm{~cm}$ which behaved in the same way. Also in this case the control treatment (CTRL) with $2.42 \mathrm{~cm}$ was the worst.The physiological analysis of the plants reflects the trend of the agronomic results (Table 2). With regard to the photosynthesis rate and chlorophyll analysis, the treatment (CM) was better, while the untreated $100 \%$ fertilized control (CTRL) was the worst. The analysis did not show any significant evidence between the treatment (CM2) and (CN). Therefore, by enriching the chabazite zeolites with microorganisms, it is possible to optimize the use of fertilizer, compared to a natural chabazite zeolites. In any case, the use of zeolites in the substrate significantly improves the agronomic and physiological performance of the plants compared to a commercial control substrate typically used by growers. 
Table 1 Evaluation of zeolitites containing Plant Growth Promoting Rhizobacteria on growth and flowering improvement on plants of Ranunculus asiaticus

\begin{tabular}{|c|c|c|c|c|c|c|}
\hline Groups & $\begin{array}{c}\text { Plants } \\
\text { height } \\
\text { (cm) }\end{array}$ & $\begin{array}{c}\text { Leaves } \\
\text { number } \\
\left(n^{\circ}\right)\end{array}$ & $\begin{array}{c}\text { Vegetative } \\
\text { weight } \\
\text { (g) }\end{array}$ & $\begin{array}{c}\text { Roots } \\
\text { weight } \\
\text { (g) }\end{array}$ & $\begin{array}{c}\text { Flowers } \\
\text { number } \\
\left(n^{\circ}\right)\end{array}$ & $\begin{array}{c}\text { Flowers } \\
\text { diameter } \\
\text { (cm) }\end{array}$ \\
\hline CTRL & $17,52^{d}$ & $30,20^{c}$ & $42,58^{c}$ & $32,24 \mathrm{~d}$ & $16,20^{c}$ & $2,42^{c}$ \\
\hline $\mathrm{CN}$ & 25,66 b & $38,40 \mathrm{~b}$ & $45,66^{b}$ & 38,64 b & $30,20^{\text {a }}$ & $3,40^{b}$ \\
\hline $\mathrm{CN} 2$ & $23,01^{c}$ & $35,40^{b}$ & $43,41 \mathrm{bc}$ & $35,76^{c}$ & $21,80 \mathrm{~b}$ & 3,02 b \\
\hline $\mathrm{CM}$ & $30,36^{a}$ & $42,80^{a}$ & $48,26^{\mathrm{a}}$ & 42,90 a & $31,40^{a}$ & $4,08^{a}$ \\
\hline CM2 & $27,17^{b}$ & $37,60^{b}$ & $45,54 \mathrm{~b}$ & $39,50 \mathrm{~b}$ & $30,40^{\mathrm{a}}$ & 3,42 b \\
\hline ANOVA & $* * *$ & $* * *$ & $* * *$ & $* * *$ & $* * *$ & $* * *$ \\
\hline
\end{tabular}

One-way ANOVA; n.s. - non significant; ${ }^{* * *},{ }^{* * *}$ - significant at $\mathrm{P} \leq 0.05,0.01$ and 0.001 , respectively; different letters for the same element indicate significant differences according to Tukey's (HSD) multiple-range test $(P=0.05)$

Table 2 Evaluation of zeolitites containing Plant Growth Promoting Rhizobacteria on the physiological parameters of Ranunculus asiaticus

\begin{tabular}{ccc}
\hline Groups & $\begin{array}{c}\text { Pn } \\
(\boldsymbol{\mu} \text { mol } \mathbf{~ m - 2 ~ s - 1 )}\end{array}$ & $\begin{array}{c}\text { Chlorophyll content } \\
\text { (spad index) }\end{array}$ \\
\hline CTRL & $11,08^{\mathrm{c}}$ & $20,61^{\mathrm{d}}$ \\
CN & $12,34^{\mathrm{b}}$ & $22,58^{\mathrm{b}}$ \\
$\mathrm{CN} 2$ & $11,40^{\mathrm{c}}$ & $21,60^{\mathrm{c}}$ \\
$\mathrm{CM}$ & $14,23^{\mathrm{a}}$ & $24,59^{\mathrm{a}}$ \\
CM2 & $12,49^{\mathrm{b}}$ & $22,88^{\mathrm{b}}$ \\
\hline ANOVA & $* * *$ & $* * *$
\end{tabular}

One-way ANOVA; n.s. - non significant; ${ }^{* * * * * * *}$ - significant at $\mathrm{P} \leq 0.05,0.01$ and 0.001 , respectively; different letters for the same element indicate significant differences according to Tukey's (HSD) multiple-range test $(\mathrm{P}=0.05)$

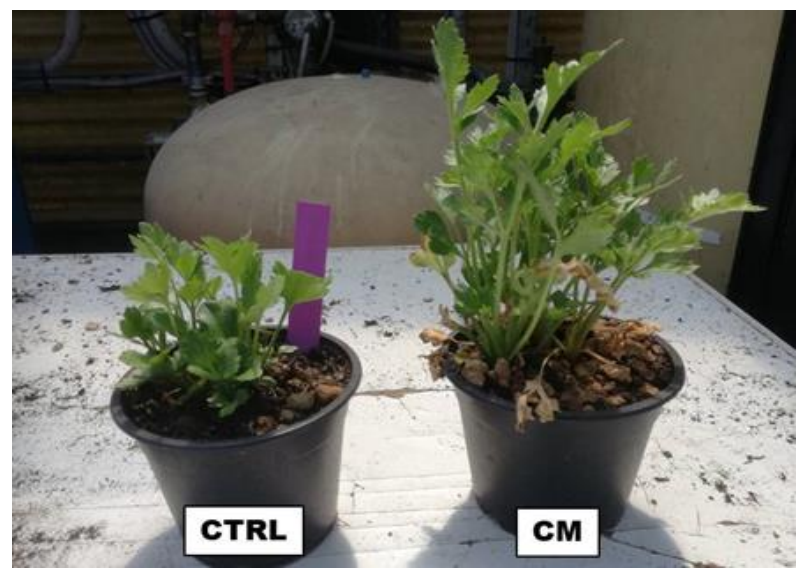

Figure 2 Effect of zeolitites containing Plant Growth Promoting Rhizobacteria on plant height of Ranunculus asiaticus. Legend: (CTRL) control; (CM) chabazite enriched with PGPR 


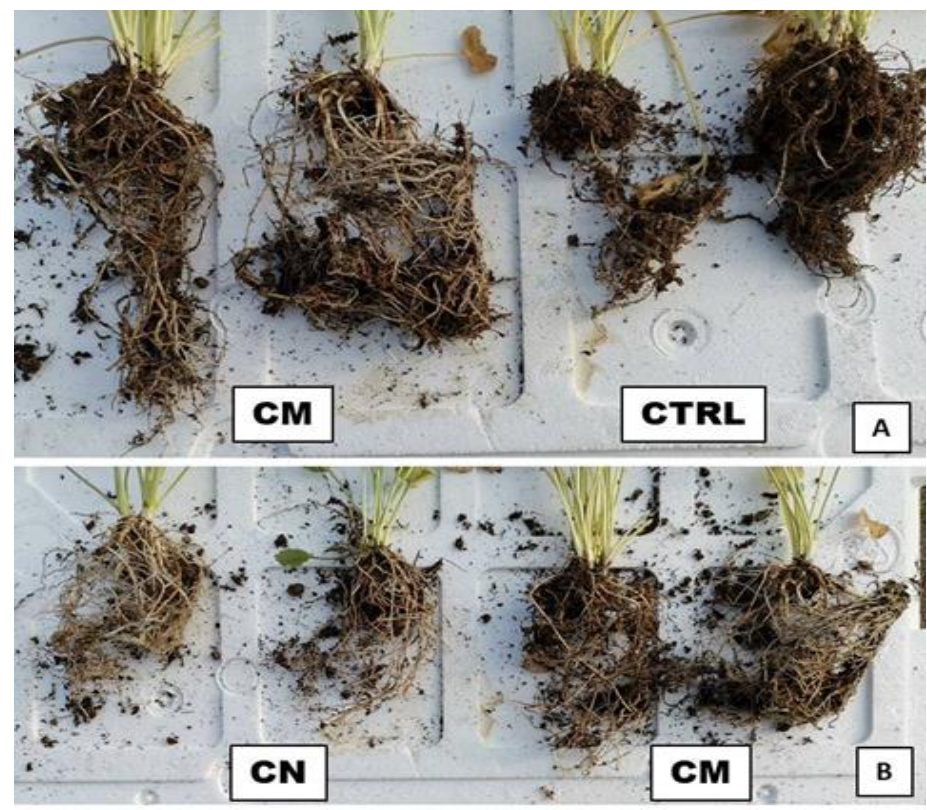

Figure 3 Effect of zeolitites containing Plant Growth Promoting Rhizobacteria on roots growth of Ranunculus asiaticus. CM vs CTRL (A) and CN vs CM (B). Legend: (CTRL) control; (CM) chabazite enriched with PGPR; (CN) natural chabazite

\section{Discussion}

Zeolites have a high cationic exchange capacity, an interesting feature is the possibility that the internal cavities of their structure can accommodate calcium, magnesium or sodium ions, and that these ions can be easily replaced by ammonium and potassium ions for which zeolites have high affinity. They are considered to be real molecular sieves and thanks to these particular properties they are used in various sectors such as water purification, petrochemical industry, animal breeding and as biostimulants in horticulture $[18,19]$.

Zeolites, in fact, once introduced in the cultivation substrata or in open field, can increase the quality of the plants, retaining water and fertilizers and making them available when needed.

In this experiment it is noted above all that the zeolite-enriched substrates for buttercup cultivation resulted in a significant increase in all the agronomic parameters analysed (plant height, number of leaves, vegetative and root biomass, number and diameter of flowers) and physiological parameters (photosynthesis rate and chlorophyll content). In particular, plants grown in chabazite with the addition of Plant Growth Promoting Rhizobacteria were significantly better than plants grown in other substrates. The presence of microorganisms in zeolite also allows an optimization of fertilizer use [20].

Chabazite is able to retain water and fertilizer at the time of fertilization, the passage of nutrients from zeolite to the plant is through microbial intervention (acidification of the substrate by microbes, release of minerals by zeolites, exchange with the plant roots that are in direct contact with Plant Growth Promoting Rhizobacteria). Obviously this mechanism can occur in a natural way even without adding the zeolite of beneficial microorganisms, but the exchange process of natural elements is significantly slower [10].

Zeolites can act as a "home" for microorganisms, as is normally the case in nature with clays. In fact, under conditions of water stress, microorganisms take refuge inside the clay particles until the environmental conditions are suitable again to colonize the soil. Zeolites are able to actively interact with the organic components present in the soil or brought with fertilization, and have the ability to make more available the mineral and nutritional components present within their crystalline lattice, according to the needs of the plant [21]. In particular, the direct contact of zeolites with the root surface stimulates the production of mucilaginous substances (mucigel) by performing a lubricating action that can facilitate the absorption by the root of minerals and water. Evidence shows that zeolites once inserted into growing substrates can lead to an improvement in the physiological aspects of plants, particularly in the net photosynthesis rate and chlorophyll content. A plant that photosynthesizes more has more energy reserves available for different metabolic functions [10]. 
These data therefore underline how the use of zeolites and in particular chabazite, in addition to improving certain aspects of plant quality and production can be crucial for the prevention and protection of certain biotic and abiotic stresses. A decisive factor in zeolites is the purity of the mineral used. The determination of the chemical-physical characteristics is in fact of particular importance in order not to run into problems during the cycle of cultivation in pots or in the open field. A new decree of March 3, 2015, proposed by Prof. Passaglia [22], indicates the non-marketability of zeolites that do not contain in their structure a content greater than $50 \%$ of that particular mineral. This assessment can only be made with the RIETVELD-RIR [16]. All this to limit the marketing of products that are not quality and to ensure that those who use this type of mineral cannot then encounter problems of phytotoxicity on plants in cultivation.

\section{Conclusion}

The test has shown that the use of zeolites enriched with Plant Growth Promoting Rhizobacteria can significantly improve the agronomic and physiological quality of buttercup plants. Zeolites once inserted into the growing medium improve the uptake of water and fertilizer by the roots and can increase the photosynthetic efficiency of the plants. The presence of beneficial microorganisms added to zeolites can further improve these aspects and provide the plant with greater protection from biotic and abiotic stress. An interesting aspect of the use of zeolite enriched with microorganisms is above all the possibility of being able to reduce by half the use of fertiliser in substrates and at the same time obtain plants with similar ornamental qualities, if not the same as those cultivated in substrates with total fertilisation, with an important saving on the purchase of the product.

\section{Compliance with ethical standards}

\section{Acknowledgments}

The research is part of the "chabamicro" project funded by the company Balco Greenline of Sassuolo (M0), in line with the project "Micronaturale": innovative techniques with low environmental impact for the cultivation and defense of plants.

\section{Disclosure of conflict of interest}

The author declares no conflict of interest.

\section{References}

[1] Parkin J. (1928). The glossy petals of Ranunculus. Ann. Bot. 4, 739-755.

[2] Galstener S, Musso M, Asembaum A and Fumkraz D. (1999). Reflectance measurements of glossy petals of Ranunculus lingua (Ranunculaceae) and of non-glossy petals of Heliopsis helianthoides (Asteraceae). Plant. Biol. 1, 670-678.

[3] Passaglia E. (2008). Zeoliti naturali - Zeolititi e loro applicazioni. ARVAN, Venezia, 99.

[4] Passaglia E, Marchi E, Barbieri L, Bedogni G, Taschini G and Azzolini P. (1997). Le zeoliti nel ciclo di depurazione delle acque reflue e loro successivo impiego in agricoltura. Noi e l'Ambiente, 52, 56-61.

[5] Bazzocchi R, Casalicchio G, Giorgioni ME, Loschi B, Passaglia E and Savelli C. (1996). Effetti di zeolititi Italiane sullo sviluppo del sedano. Colture Protette, 11, 91-97.

[6] Prisa D. (2019). Cultivation and cold stress protection in Crassula with zeolitites. The International Journal of Engineering and Science (IJES), 8(6) Series I, 29-34.

[7] Passaglia E and Poppi S. (2005). Risparmio idrico e di fertilizzanti nella coltivazione di ortaggi e frutta in terreni ammendati con zeolitite a chabasite. In: Atti $3^{\circ}$ Convegno AISSA "Il pianetaacquanelcontinenteagricoltura", Facoltà di Agrariadell'Università di Modena e Reggio Emilia, 6-7 Dicembre, 109-110.

[8] Passaglia E and Poppi S. (2005). Strong reduction of irrigation water and fertilizers for vegetable and fruitgrowing on soilsamended with Italianchabaziterich rock. Epitome, 1, 2005. FIST - Federazione Italiana di Scienze della Terra. GeoItalia 2005 - Quinto Forum Italiano di Scienze della Terra, Spoleto, 21-23 Settembre, 96.

[9] Prisa D. (2019). Germination Of Vegetable and Grassland species With Micronized chabazitic-Zeolites And Endophytic Fungi. IOSR Journal of Agriculture and Veterinary Science, 12(5), 32-37. 
[10] Prisa D. (2019). Effect of natural zeolites and zeolites added with microorganisms for the growth of cabbage (Brassica oleracea var. capitata L.). World Journal of Advanced Research and Reviews, 04(01), 006-012.

[11] Prisa D. (2019). Effective Microorganisms and Chabazitic-Zeolites For The Improvement Quality Of Echinopsis Hybrids. Asian Academic Research Journal of Multidisciplinary, 6(2), 23-34.

[12] Prisa D. (2019). Effect of chabazitic-zeolites and effective microorganisms on growth and chemical composition of Aloe barbadensis Miller and Aloe arborescens Miller. International Journal of Agricultural Research, Sustainability, and Food Sufficiency (IJARSFS), 6(01), 315-321.

[13] Prisa D. (2019). Improvement Quality Of Impatiens And Oleander Plants With Chabazitic-Zeolites. International Journal of Recent Scientific Research, 10(04), 31727-31730.

[14] Prisa D. (2019). Rhizobacteria and zeolites for overcoming saline stress in the cultivation of succulent plants. The International Journal of Engineering and Science (IJES), 8(5) Series I, 38-41.

[15] Prisa D. (2019). Zeolites as additives for the rooting of Camellia japonica and Proteaceae Juss. The International Journal of Engineering and Science (IJES), 8(5) Series I, 10-14.

[16] Gualtieri AF. (2000). Study of NH4+ in the zeolite phillipsite by combined synchrotron powder diffraction and IR spectroscopy. Acta Cryst., B56, 584-593.

[17] Gualtieri AF, Marchi E and Passaglia E. (1999). Zeolite content and cation exchange capacity of zeolite-rich rocks. Studies in Surface Science and Catalysis, 125, 707-713.

[18] Nwugo CC and Huerta AJ. (2008). Effect of silicon nutrition on cadmum uptake, growth and photosynthesis of rice plant exposed to low-level cadmium. Plant and soil, 311, 73-86.

[19] Savvas D, Giotis D, Chatzieustratiou E, Bakea N and Patakioutas G. (2009). Silicon supply in soilless cultivations of zucchini alleviates stress induced by salinity and powdery mildew infections. Environmental and Experimental Botany, 65(1), 11-17.

[20] Prisa D. (2018). Italian chabazitic-zeolitite and Effective microorganisms for the qualitative improvement of olive trees. Atti del Convegno di Calci (PI) 2017 Atti Soc. Tosc. Sci. Nat., 125, 13-17.

[21] Mackown CT and Tucker TC. (1985). Ammonium nitrogen movement in a coarse-textured soil amended with zeolite. Soil Science Society of America Journal, 49(2), 225-238.

[22] Passaglia E and Prisa D. (2018). Contributo delle zeolititi nella mitigazione delle problematiche ambientali conseguenti alle vigenti pratiche agricole. Ediazioni lulu, 155.

\section{How to cite this article}

Prisa D. (2020). Optimised fertilisation with zeolitites containing Plant Growth Promoting Rhizobacteria (PGPR) in Ranunculus asiaticus. GSC Biological and Pharmaceutical Sciences, 10(1), 96-102. 